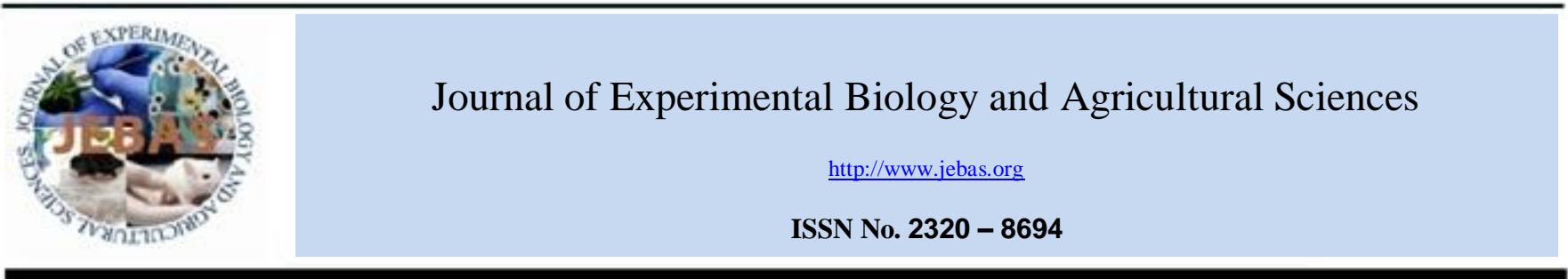

\title{
EFFECT OF L-PENICILLAMINE, N-ACETYL CYSTEINE AND $\alpha$-TOCOPHEROL ACETATE ON BUFFALO (BUBALUS BUBALIS) SPERM KINEMATICS IN VITRO
}

\author{
Sharanabasav Badami, Sudhir C. Roy*, Arindam Dhali \\ Molecular Biology Laboratory, ICAR-National Institute of Animal Nutrition and Physiology, Hosur Road, Adugodi, Bangalore-560030, India \\ Received - July 04, 2018; Revision - September 25, 2018; Accepted - November 10, 2018 \\ Available Online - December 15, 2018
}

DOI: http://dx.doi.org/10.18006/2018.6(6).990.996

KEYWORDS
Buffalo
n-acetyl cysteine
L-penicillamine
-tocopherol acetate
Sperm motility

\begin{abstract}
The post-thaw viability and motility of buffalo sperm are reduced significantly when they are cryopreserved. One of the etiologies of this reduced post-thaw viability and motility of buffalo sperm has been attributed to cryopreservation-associated generation of reactive oxygen species (ROS) in sperm. Hence, there is an urgent need to address this issue by incorporating some of the external additives which can reduce or scavenge the production of ROS. Sperm were separated from seminal plasma as it contains many identified and unidentified motility stimulating/inhibiting factors that may interfere in the interpretation of any action of external agent. Thus, in the present study, sperm were

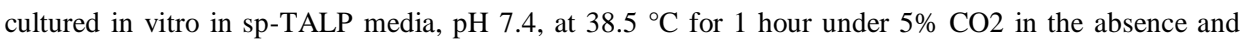
presence of L-penicillamine, $\mathrm{n}$-acetyl cysteine and $\alpha$-tocopherol acetate. The sperm kinematics was studied using computer-assisted semen analyzer (CASA). The results revealed that $0.25 \mathrm{mM} \mathrm{L}$ penicillamine could increase the total motility, progressive motility, rapid motility, amplitude of lateral head displacement (ALH) and beat cross frequency (BCF) of buffalo sperm as compared to the control group. Similarly, $600 \mu \mathrm{M} \alpha$-tocopherol acetate could increase the total motility, rapid motility, curvilinear velocity, straight-line velocity, ALH and BCF of sperm. However, n-acetyl cysteine at the tested concentrations $(0.125-1.0 \mathrm{mM})$ could not increase the sperm kinematics parameters. Thus, Lpenicillamine and $\alpha$-tocopherol acetate were found to be two promising additives for improving buffalo sperm motility. However, effect of pre-freeze addition of these additives to the semen extender on postthaw motility of buffalo sperm warrants further investigation.
\end{abstract}

* Corresponding author

E-mail: scroy67@gmail.com; scroy67@yahoo.co.in (Dr. Sudhir C. Roy, Principal Scientist)

Peer review under responsibility of Journal of Experimental Biology and Agricultural Sciences.

Production and Hosting by Horizon Publisher India [HPI] (http://www.horizonpublisherindia.in/).

All rights reserved.
All the article published by Journal of Experimental Biology and Agricultural Sciences is licensed under a Creative Commons Attribution-NonCommercial 4.0 International License Based on a work at www.jebas.org.

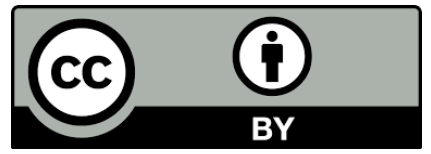




\section{Introduction}

Reactive Oxygen Species (ROS), also referred to as free radicals, are formed as an essential byproducts of aerobic respiration in mitochondria and required to drive physiological inter and intracellular signaling. ROS are highly reactive species due to the presence of an unpaired electron in their outermost shell and depending on their concentration they can be beneficial or harmful to cells and tissues (Halliwell \& Gutteridge, 1989). In mammalian spermatozoa, at physiological concentrations, ROS are produced normally and required to cater diverse physiological functions, however, when generated in excess, these species cause oxidative stress (Aitken \& Curry, 2011). Mammalian spermatozoa are vulnerable to oxidative stress due to the presence of limited cytoplasmic antioxidant enzymes. Consequently, when the generation of ROS overwhelms the sperm's antioxidant defense mechanism, it causes detrimental effects on the functional competence of sperm through the peroxidation of lipids (Alvarez et al., 1987; Alvarez \& Storey 1992), DNA (Duru et al., 2000), and proteins (Alvarez et al., 1987; Aitken \& Clarkson, 1988; de Lamirande \& Gagnon, 1992) and affects the sperm motility. Hence, the above work indicated that antioxidant elements of sperm play a pivotal role in preserving both functional and structural integrity of spermatozoa.

Semen cryopreservation is an essential tool to preserve and propagate the elite germplasm in livestock. However, the process of cryopreservation has been reported to be associated with increased generation of ROS and induction of oxidative stress with the concomitant reduction in sperm viability, motility and fertilizing potential (Thomson et al., 2009). Further, during cryopreservation, a large amount of sperm cytoplasmic components including antioxidants are leaked out (Bilodeau et al., 2000; Kar et al., 2015). Thus, the sperm antioxidant capacity is not sufficient for long term storage and cryopreservation of semen. Hence, supplementation of any external antioxidants/additives that could reduce the impact of oxidative stress and thereby improve the post-thaw sperm viability and motility may be one of the solutions. Different agents having antioxidant property are being used in different species for improving the post-thaw sperm functions. Addition of Lpenicillamine at $75 \mathrm{mM}$ concentration increased the motility in vitro of ram sperm (El-Shahat et al., 2017). Similarly, addition of $\mathrm{N}$-acetyl-L-cysteine at $15 \mathrm{mM}$ increased significantly the progressive motility of chicken sperm during liquid storage at 5 ${ }^{\circ} \mathrm{C}$ (Partyka et al., 2015). Pre-freeze addition of Trolox, a vitamin $\mathrm{E}$ analogue, at $200 \mu \mathrm{M}$ concentration increased significantly the post-thaw motility of rabbit spermatozoa (Zhu et al., 2015). However, the optimum concentration of the additive has to be determined for each species prior to incorporation in the freezing medium. Thus, the present study was undertaken to determine the optimum concentrations of three additives such as Lpenicillamine, n-acetyl cysteine and $\alpha$-tocopherol acetate. Further, seminal plasma is a mixture of varieties of biomolecules and other motility stimulating and inhibiting factors (de Lamirande et al., 1984; Robert \& Gagnon, 1996; Juyena \& Stelleta, 2012). It is possible that some of the factor of the seminal plasma may interact with the test agent and may interfere in our conclusion. Thus, to study the effect of a particular additive on sperm functions, the spermatozoa were separated from seminal plasma and cultured in the presence of the test additive in defined media. The results of this study could provide definitive picture about the optimum concentration of each additive that could be non-lethal but motility enhancer, and can be incorporated into the freezing medium prior to the cryopreservation.

\section{Materials and Methods}

\subsection{Animals}

Four healthy Murrah buffalo (Bubalus bubalis) bulls, 3-5 years of age, weighing 450 to $740 \mathrm{~kg}$, were maintained under uniform feeding and management regimen at Nandini Sperm Station, Hessarghatta, Bangalore. All the experimental protocols of the study were carried out following the Institutional Animal Ethics Committee guidelines.

\subsection{Collection of neat semen and preparation of spermatozoa}

Semen was collected twice a week from each bull using an artificial vagina (IMV Technologies, L'Aigle, France) maintained at $40{ }^{\circ} \mathrm{C}$. In a day, two ejaculates were collected from each bull after an interval of approximately 30 minutes and both the ejaculates of the same bull were pooled and this constituted one semen sample. Freshly ejaculated semen samples were collected from buffalo and were assessed for their mass activities by light microscopy at $10 \mathrm{X}$ magnifications. The semen samples having progressive motility $\geq 75 \%$ only were used in the study. Aliquots of the neat semen samples were collected in $15 \mathrm{~mL}$ centrifuge tubes and transported to the laboratory within 2 hours in thermos flask maintained at $37^{\circ} \mathrm{C}$. The semen samples were diluted in 1:6 ratios with a modified Tyrode's Hepes-buffered medium designated as sp-TALPH, pH 7.4 [composed of $100 \mathrm{mM} \mathrm{NaCl}$, $3.1 \mathrm{mM} \mathrm{KCl}, 0.4 \mathrm{mM}$ EDTA, $0.4 \mathrm{mM} \mathrm{\textrm {Mgl } _ { 2 }} \bullet 6 \mathrm{H}_{2} \mathrm{O} ; 0.3 \mathrm{mM}$ $\mathrm{NaH}_{2} \mathrm{PO}_{4} \bullet 2 \mathrm{H}_{2} \mathrm{O}, 21.6 \mathrm{mM}$ Na lactate, $2 \mathrm{mM} \mathrm{CaCl}_{2} \bullet 2 \mathrm{H}_{2} \mathrm{O}, 1$ $\mathrm{mM}$ Na pyruvate, $40 \mathrm{mM}$ Hepes, $10 \mathrm{mM} \mathrm{NaHCO}_{3}$, and polyvinyl alcohol (PVA, 30-70 kDa; $1 \mathrm{mg} / \mathrm{mL}$ )] and subjected to two washes by centrifugation at $350 \mathrm{x}$ g for 5 minutes at $25^{\circ} \mathrm{C}$ in the same media. The final wash was carried out at $350 \mathrm{x}$ g for 5 minutes at $25{ }^{\circ} \mathrm{C}$ to remove the sp-TALPH, pH 7.4 medium. The sperm pellets were resuspended in double the volume of sp-TALP, $\mathrm{pH}$ 7.4 [Modiified Tyrode's bicarbonate-buffered medium containing the same ingredients as stated above except it contained $10 \mathrm{mM}$ 
Hepes instead of $40 \mathrm{mM}, 25 \mathrm{mM} \mathrm{NaHCO}$ instead of $10 \mathrm{mM}$ and BSA $(1 \mathrm{mg} / \mathrm{mL})$ instead of PVA] and the sperm concentration was determined by haemocytometer. The concentration of sperm suspensions were adjusted to $80 \times 10^{6}$ cells $/ \mathrm{mL}$ with sp-TALP, $\mathrm{pH} 7.4$.

\subsection{Effect of various concentrations of additives on buffalo sperm kinematics in vitro}

To study the effect of various concentrations of additives on buffalo sperm kinematics, buffalo sperm were cultured in vitro at a concentration of $40 \times 10^{6}$ cells $/ \mathrm{mL}$ in sp-TALP, $\mathrm{pH} 7.4$ in the absence or presence of the various additives such as $0.25,0.50$ and $0.75 \mathrm{mM}$ L-penicillamine, $0.125,0.25$ and $1.0 \mathrm{mM}$-acetyl cysteine and 200, 400 and $600 \mu \mathrm{M} \alpha$-tocopherol acetate at $38.5^{\circ} \mathrm{C}$ for 1 hour under $5 \% \mathrm{CO}_{2}$. The effect of each concentration of an additive was assessed by dispensing $250 \mu \mathrm{L}$ aliquots of $80 \times 10^{6}$ cells/mL sp-TALP, $\mathrm{pH} 7.4$ to different $1.5 \mathrm{~mL}$ microcentrifuge tubes containing $250 \mu \mathrm{L}$ of sp-TALP, $\mathrm{pH} 7.4$ added with desired concentrations of additives to attain a final concentration of additives. These additives treated sperm suspensions were cultured in vitro in $\mathrm{CO}_{2}$ incubator [NB-203, N-BIOTEK Inc. Lab System, South Korea] at $38.5{ }^{\circ} \mathrm{C}$ under $5 \% \mathrm{CO}_{2}$ for 1 hour. After incubation, the sperm suspensions were diluted 5 times to attain final sperm concentration of $8 \times 10^{6} / \mathrm{mL}$ with pre-warmed spTALP, pH 7.4 and immediately subjected for analysis of various sperm motility parameters such as total motility, progressive motility, rapid motility, curvilinear velocity (VCL), straight-line velocity (VSL), average path velocity (VAP), amplitude of lateral head displacement (ALH) and beat/cross frequency (BCF) using computer-assisted semen analyzer (CASA, version 3.2.0; Microptic, Barcelona, Spain) according to the method of Dott \& Foster (1979).

\subsection{Statistical analysis}

Data were analyzed by ANOVA using SPSS, version 10.0.1 software (SPSS Inc., Chicago, IL, USA). Data are presented as mean \pm standard error of the mean (SEM). A difference with the value $\mathrm{P}<0.05$ was considered statistically significant.

\section{Results and Discussion}

Semen cryopreservation is an essential technique for propagation and storage of livestock semen. However, it is associated with low post-thaw motility and fertility of sperm leading to reduced conception rate. Several earlier reports have already established that the cryopreserved sperm undergo a significant degree of structural and functional changes due to damage and modification to its lipids, proteins and DNA (Watson, 2000; Andrabi, 2009; Thomson et al., 2009; Aitken, 2017).

Recently, these cryopreservation-associated biomolecular changes are being studied in human, boar, stallion, ram, canine and bull
(Brouwers et al., 2005; Neild et al., 2005; Peris et al., 2007; Kim et al., 2010; Mostek et al., 2017). The principal causative factor for the above biomolecular changes have been attributed to the production of ROS during and after cryopreservation of semen. However, details of the above biomolecular changes in terms of lipid peroxidation (LPO), protein oxidation and nuclear damage are less studied for the semen of domestic animals including buffalo. Moreover, reports pertaining to any additives or additives that can reduce these biomolecular changes are also very limited (Partyka et al., 2015; Zhu et al., 2015; El-Shahat et al., 2017).

A mammalian spermatozoon demonstrates various types of motility parameters such as total motility, progressive motility, rapid motility, curvilinear velocity (VCL), straight-line velocity (VSL), average path velocity (VAP), amplitude of lateral head displacement (ALH) and beat/cross frequency (BCF) under different physiological conditions (Mortimer \& Mortimer, 1990). After ejaculation, a mammalian spermatozoon demonstrates progressive motility, which is characterized by highest VCL, VSL, VAP, ALH and high BCF (Cremades et al., 2005). After capacitation in the female reproductive tract or culture in vitro in a capacitating medium, a mammalian spermatozoon display hyperactive motility which is characterized by movement of tail in the form of figure of " 8 " with higher values of VCL and ALH together with moderate BCF (Muino et al., 2009).

In the present study, in $0.25 \mathrm{mM}$ L-penicillamine treatment group, the total motility, progressive motility, rapid motility, amplitude of lateral head displacement and beat cross frequency of spermatozoa were increased $(\mathrm{P}=0.081, \mathrm{P}=0.125, \mathrm{P}=0.109$, $\mathrm{P}=0.635$ and $\mathrm{P}=0.431$, respectively) as compared to the control group (without L-penicillamine treatment) (Table.1). There was a marginal decrease $(\mathrm{P}=0.199, \mathrm{P}=0.151$ and $\mathrm{P}=0.214)$ in $\mathrm{VCL}, \mathrm{VSL}$ and VAP of spermatozoa in this treatment group as compared to control group (Table.1). In $0.50 \mathrm{mM}$ and $0.75 \mathrm{mM} \mathrm{L-}$ penicillamine treatment group, the total motility, progressive motility, amplitude of lateral head displacement and beat cross frequency of spermatozoa were increased $(\mathrm{P}=0.071$ \& $\mathrm{P}=0.469$; $\mathrm{P}=0.143$ \& $\mathrm{P}=0.175 ; \mathrm{P}=0.184$ \& $\mathrm{P}=0.300 ;$ and $\mathrm{P}=0.317$ \& $\mathrm{P}=0.381$, respectively) as compared to control group (H; Table.1). However, 0.50 and $0.75 \mathrm{mM}$ L-penicillamine treatment groups tend to reduce sperm rapid motility, VCL, VSL and VAP $(\mathrm{P}=0.501 \& \mathrm{P}=0.754 ; \mathrm{P}=0.103 \& 0.091 ; \mathrm{P}=0.108 \& \mathrm{P}=0.084$ and $\mathrm{P}=0.102 \& \mathrm{P}=0.082$ ) of spermatozoa as compared to control group spermatozoa (Table 1)

L-penicillamine, an amino acid derivative, also a metal chelating agent, when added in vitro at $0.25 \mathrm{mM}$ concentration to the sperm suspension in sp-TALP, pH 7.4 media, could increase progressive motility and rapid motility. Thus, $0.25 \mathrm{mM}$ L-penicillamine was found to be a promising semen extender additive for buffalo sperm. Earlier, L-penicillamine has been reported to increase 
Table 1 Motility parameters of buffalo sperm after treatment with L-penicillamine in sp-TALP, pH 7.4, at $38.5^{\circ} \mathrm{C}$ for 1 hour under $5 \% \mathrm{CO}_{2}$.

\begin{tabular}{|ccccc|}
\hline Parameter & Control & $\begin{array}{c}0.25 \mathrm{mM} \\
\text { L-penicillamine }\end{array}$ & $\begin{array}{c}0.5 \mathrm{mM} \\
\text { L-penicillamine }\end{array}$ & $\begin{array}{c}0.75 \mathrm{mM} \\
\text { L-penicillamine }\end{array}$ \\
\hline Total motility & $85.43 \pm 0.42$ & $90.97 \pm 1.27$ & $88.50 \pm 0.67$ & $87.67 \pm 2.14$ \\
\hline $\begin{array}{c}\text { Progressive } \\
\text { motility }\end{array}$ & $76.20 \pm 1.70$ & $82.70 \pm 3.05$ & $78.23 \pm 1.68$ & $80.47 \pm 2.54$ \\
\hline Rapid motility & $78.13 \pm 3.37$ & $87.50 \pm 0.12$ & $74.47 \pm 7.79$ & $76.27 \pm 1.84$ \\
\hline VCL & $102.67 \pm 4.09$ & $97.10 \pm 5.91$ & $81.20 \pm 11.38$ & $79.93 \pm 6.97$ \\
\hline VSL & $89.37 \pm 3.24$ & $82.77 \pm 5.22$ & $67.00 \pm 10.85$ & $66.03 \pm 6.90$ \\
\hline VAP & $97.00 \pm 4.26$ & $90.73 \pm 7.11$ & $73.53 \pm 12.23$ & $71.43 \pm 8.57$ \\
\hline ALH & $1.87 \pm 0.09$ & $1.93 \pm 0.15$ & $1.93 \pm 0.09$ & $2.03 \pm 0.15$ \\
\hline BCF & $8.80 \pm 0.35$ & $9.33 \pm 0.43$ & $9.30 \pm 0.50$ & $9.70 \pm 0.78$ \\
\hline
\end{tabular}

Data are mean+SEM of three replicates

Table 2 Motility parameters of buffalo sperm after treatment with n-acetyl cysteine in sp-TALP, $\mathrm{pH} 7.4$, at $38.5^{\circ} \mathrm{C}$ for 1 hour under $5 \% \mathrm{CO}_{2}$.

\begin{tabular}{|lllll|}
\multicolumn{1}{c}{ Parameter } & \multicolumn{1}{c}{ Control } & \multicolumn{1}{c|}{$0.125 \mathrm{mMNAC}$} & \multicolumn{1}{c|}{$0.25 \mathrm{mM} \mathrm{NAC}$} & \multicolumn{1}{c|}{ mM NAC } \\
\hline Total motility & $94.90 \pm 1.30$ & $96.33 \pm 1.27$ & $95.90 \pm 0.89$ & $97.20 \pm 0.83$ \\
\hline Progressive motility & $85.25 \pm 1.45$ & $80.08 \pm 2.76$ & $78.35 \pm 4.16$ & $79.00 \pm 1.20$ \\
\hline Rapid motility & $93.50 \pm 1.30$ & $94.00 \pm 1.65$ & $93.03 \pm 1.81$ & $94.05 \pm 1.43$ \\
\hline VCL & $123.98 \pm 6.7$ & $125.80 \pm 4.11$ & $118.25 \pm 4.06$ & $120.13 \pm 3.20$ \\
\hline VSL & $105.90 \pm 4.85^{\mathrm{a}}$ & $102.53 \pm 3.14^{\mathrm{a}}$ & $96.78 \pm 4.39^{\mathrm{b}}$ & $96.28 \pm 2.27^{\mathrm{b}}$ \\
\hline VAP & $118.38 \pm 5.6$ & $119.33 \pm 3.92$ & $113.10 \pm 4.34$ & $113.95 \pm 2.92$ \\
\hline ALH & $1.93 \pm 0.08$ & $2.03 \pm 0.03$ & $1.88 \pm 0.08$ & $1.95 \pm 0.06$ \\
\hline BCF & $8.30 \pm 0.39$ & $8.40 \pm 0.25$ & $7.80 \pm 0.22$ & $7.60 \pm 0.07$ \\
\hline
\end{tabular}

Data are mean+SEM of four replicates. Different letter above the figures indicate significant differences between the groups (P $\leq 0.05)$.

motility of equine, human and rat sperm (Aitken et al., 2012). Lpenicillamine preserves the sperm motility by preventing the loss of critical sperm protein thiols from the mitochondrial ROS products (Aitken et al., 2012). Recently, L-penicillamine has been found to prevent ram sperm agglutination by reducing the disulphide bonds of a copper-binding protein present on the sperm plasma membrane (Leahy et al., 2016).

In $0.125 \mathrm{mM}$ n-acetyl cysteine treatment group, the total motility, rapid motility, VCL, VAP, ALH and BCF of spermatozoa were increased but non-significant $(\mathrm{P}=0.323, \mathrm{P}=0.827, \mathrm{P}=0.740$, $\mathrm{P}=0.848, \mathrm{P}=0.182$ and $\mathrm{P}=0.664$, respectively, Table.2), whereas progressive motility and VSL of spermatozoa were decreased non-significantly $(\mathrm{P}=0.132$ and $\mathrm{P}=0.576$, respectively, Table. 2$)$ as compared to control group (without $n$-acetyl cysteine treatment). In other groups such as 0.25 and $1.0 \mathrm{mM}$ n-acetyl cysteine treatment groups, the VSL of spermatozoa was significantly decreased ( $\mathrm{P} \leq 0.05$, Table 2$)$, and there was a marginal decrease in progressive motility, VCL, VAP and $\mathrm{BCF}(\mathrm{P}=0.145$ \& $\mathrm{P}=0.062 ; \mathrm{P}=0.223$ \& $\mathrm{P}=0.392 ; \mathrm{P}=0.165 \& \mathrm{P}=0.295 ;$ and $\mathrm{P}=0.262$ \& $\mathrm{P}=0.144$, respectively, Table.2) as compared to the control group.

$\mathrm{N}$-acetylcysteine, an another amino acid derivative and also a nucleophilic thiol, when added at different concentrations such as $0.125,0.25$ and $1 \mathrm{mM}$ to buffalo sperm suspension cultured in vitro in sp-TALP, $\mathrm{pH} 7.4$, could not improve any sperm motility parameters. However, in an earlier report, the same agent at 0.25 and $1.0 \mathrm{mM}$ concentration could increase the progressive motility of human spermatozoa (Aitken et al., 2012). This may be attributed to the species-specific variation in sensitivity of a particular agent towards the sperm.

In $200 \mu \mathrm{M} \alpha$-tocopherol acetate treatment group, progressive motility, VCL, VSL and VAP of spermatozoa was decreased nonsignificantly $\quad(\mathrm{P}=0.149, \quad \mathrm{P}=0.434, \quad \mathrm{P}=0.263$ and $\mathrm{P}=0.340$, 
Table 3 Motility parameters of buffalo sperm after treatment with $\alpha$-tocopherol acetate in sp-TALP, pH 7.4 , at $38.5^{\circ} \mathrm{C}$ for 1 hour under $5 \% \mathrm{CO}_{2}$.

\begin{tabular}{|ccccc|}
\hline Parameter & Control & $200 \mu \mathrm{M}$ ATA & $400 \mu \mathrm{M}$ ATA & $600 \mu \mathrm{M}$ ATA \\
\hline Total motility & $94.90 \pm 1.30$ & $96.25 \pm 0.51$ & $96.23 \pm 0.60$ & $96.93 \pm 1.29$ \\
\hline Progressive motility & $85.25 \pm 1.45$ & $82.18 \pm 1.39$ & $82.65 \pm 1.77$ & $84.30 \pm 1.31$ \\
\hline Rapid motility & $93.50 \pm 1.30$ & $94.75 \pm 0.48$ & $93.90 \pm 0.76$ & $94.73 \pm 2.43$ \\
\hline VCL & $123.98 \pm 6.7$ & $118.73 \pm 1.80$ & $118.28 \pm 5.39$ & $124.10 \pm 5.06$ \\
\hline VSL & $105.9 \pm 4.85$ & $98.85 \pm 1.39$ & $99.08 \pm 4.29$ & $106.35 \pm 5.54$ \\
\hline VAP & $118.38 \pm 6.0$ & $112.10 \pm 1.68$ & $111.63 \pm 4.82$ & $117.78 \pm 5.07$ \\
\hline ALH & $1.93 \pm 0.08$ & $1.95 \pm 0.03$ & $1.80 \pm 0.27$ & $2.05 \pm 0.03$ \\
\hline BCF & $8.30 \pm 0.39$ & $8.58 \pm 0.26$ & $7.70 \pm 1.22$ & $9.03 \pm 0.34$ \\
\hline
\end{tabular}

Data are the mean of four replicates

respectively, Table 3), with simultaneous marginal increase in total motility, rapid motility, ALH and BCF $(\mathrm{P}=0.438, \mathrm{P}=0.435$, $\mathrm{P}=0.638$ and $\mathrm{P}=0.631$, respectively, Table 3 ) of spermatozoa as compared to the control group. In $400 \mu \mathrm{M} \alpha$-tocopherol acetate treatment group, the spermatozoa exhibited a minor decrease in progressive motility, VCL, VSL, VAP, ALH and BCF ( $\mathrm{P}=0.192$, $\mathrm{P}=0.505, \mathrm{P}=0.405, \mathrm{P}=0.401, \mathrm{P}=0.651$ and $\mathrm{P}=0.625$, respectively, Table 3), with simultaneous marginal increase in total motility and rapid motility $(\mathrm{P}=0.467$ and $\mathrm{P}=0.755$, respectively, Table 3$)$ as compared to the control group. In $600 \mu \mathrm{M} \alpha$-tocopherol acetate treatment group, the total motility, rapid motility, VCL, VSL, ALH and BCF of spermatozoa were increased $(\mathrm{P}=0.095, \mathrm{P}=0.541$, $\mathrm{P}=0.982, \quad \mathrm{P}=0.938, \quad \mathrm{P}=0.239$ and $\mathrm{P}=0.238$, respectively) as compared to spermatozoa of control group (Table 3 ).

$\alpha$-tocopherol acetate is a small-molecule chain breaking antioxidant; this feature neutralizes lipid radicals and offers membrane protection. Addition in vitro of $600 \mu \mathrm{M}$ concentration to the sperm suspension in sp-TALP, pH 7.4 media, increased the total motility, rapid motility, VCL, VSL, ALH and BCF of spermatozoa. Earlier studies in boar have demonstrated that $\alpha$ tocopherol can prevent oxidative damage by breaking the ROS induced covalent links between the fatty acid side chains of membrane lipids and thereby improving post-thaw sperm viability and motility (Breininger et al., 2005; Jeong et al., 2009).

\section{Conclusion}

The present study demonstrated that in vitro treatment of buffalo spermatozoa in sp-TALP, pH 7.4 medium with $0.25 \mathrm{mM} \mathrm{L-}$ penicillamine, $600 \mu \mathrm{M} \alpha$-tocopherol acetate improved the sperm kinematics as compared to the untreated control group. Hence, these two additives were found to be promising for incorporation in to the semen extender prior to the cryopreservation to improve post-thaw sperm motility, however, this can be confirmed by another set of experiments. $\mathrm{N}$-acetyl cysteine could not improve sperm motility parameters. Thus, further investigation is required with other concentrations of n-acetyl cysteine.

\section{Acknowledgement}

The authors express their sincere thanks to the Director, National Institute of Animal Nutrition and Physiology (NIANP), Bangalore for providing the fund and research facilities to carry out the work. The authors also thank the Director and staff of Nandini Sperm Station, Hessarghatta, Bangalore for providing the semen samples for the present study. The first author also thanks the Director, Indian Veterinary Research Institute (IVRI), Izatnagar, Bareilly, UP, India for providing an opportunity to him to pursue the research work at NIANP, Bangalore and supporting him through IVRI Institute Fellowship.

\section{Conflict of Interest}

The authors declare that there is no conflict of interest regarding the publication of this research paper.

\section{References}

Aitken RJ (2017) Reactive oxygen species as mediators of sperm capacitation and pathological damage. Molecular Reproduction and Development 84:1039-1052.

Aitken RJ, Clarkson JS (1988) Significance of reactive oxygen species and antioxidants in defining the efficacy of sperm preparation techniques. Journal of Andrology 9: 367-376.

Aitken RJ, Curry BJ (2011) Redox regulation of human sperm function: from the physiological control of sperm capacitation to the etiology of infertility and DNA damage in the germ line. Antioxidants \& Redox Signaling 14: 367-381. 
Aitken RJ, Gibb Z, Mitchell LA, Lambourne SR, Connaughton HS, De Iuliis GN (2012) Sperm motility is lost in vitro as a consequence of mitochondrial free radical production and the generation of electrophilic aldehydes but can be significantly rescued by the presence of nucleophilic thiols. Biology of Reproduction 87: 110.

Alvarez JG, Storey BT (1992) Evidence for increased lipid peroxidative damage and loss of superoxide dismutase activity as a mode of sublethal cryodamage to human sperm during cryopreservation. Journal of Andrology 13: 232-241.

Alvarez JG, Touchstone JC, Blasco L, Storey BT (1987) Spontaneous lipid peroxidation and production of hydrogen peroxide and superoxide in human spermatozoa: superoxide dismutase as a major enzyme protectant against oxygen toxicity. Journal of Andrology 8: 338-348.

Andrabi SMH (2009) Factors affecting the quality of cryopreserved buffalo (Bubalus bubalis) bull spermatozoa. Reproduction in Domestic Animals 44: 552-569.

Bilodeau JF, Chatterjee S, Sirard MA, Gagnon C (2000) Levels of antioxidant defenses are decreased in bovine spermatozoa after a cycle of freezing and thawing. Molecular Reproduction and Development 55: $282-88$.

Breininger E, Beorlegui NB, O’Flaherty CM, Beconi MT (2005) Alphatocopherol improves biochemical and dynamic parameters in cryopreserved boar semen. Theriogenology 63: 2126-2135.

Brouwers JF, Silva PFN, Gadella BM (2005) New assays for detection and localization of endogenous lipid peroxidation products in living boar sperm after BTS dilution or after freezethawing. Theriogenology 63: 458-469.

Cremades T, Roca J, Rodriguez-Martinez H, Abaigar T, Vazquez JM, Martinez EA (2005) Kinematic changes during the cryopreservation of boar spermatozoa. Journal of Andrology 26: 610-618.

De Lamirande E, Belles-isles M, Gagnon C (1984) Characteristics of a seminal plasma inhibitor of sperm motility. Annals of the New York Academy of Sciences 438: 125-131.

de Lamirande E, Gagnon C (1992) Reactive oxygen species and human spermatozoa. I. Effects on the motility of intact spermatozoa and on sperm axonemes. Journal of Andrology 13: 368-78.

Dott HM, Foster GCA (1979) The estimation of sperm motility in semen, on a membrane slide, by measuring the area change frequency with an image analyzing computer. Journal of Reproduction and Fertility 55: 161-166.

Duru N, Morshedi M, Oehninger S (2000) Effects of hydrogen peroxide on DNA and plasma membrane integrity of human spermatozoa. Fertility and Sterility 74: 1200-1207.
El-Shahat KH, Taysser MI, Badr MR, Zaki KA (2017). Effects of penicillamine, hypotaurine, and epinephrine on motility, hyperactivity, acrosome reaction of fresh ram sperm. Asian Pacific Journal of Reproduction 6: 283-288.

Halliwell B, Gutteridge JMC (1989) Free Radical Biology and Medicine. 2nd Edition. Oxford: Oxford University Press.

Jeong YJ, Kim MK, Song HJ, Kang EJ, Ock SA, Kumar M, Balasubramanian S, Rho GJ (2009) Effect of alphatocopherol supplementation during boar semen cryopreservation on sperm characteristics and expression of apoptosis related genes. Cryobiology 58: 181-189.

Juena NS, Stellata C (2012) Seminal plasma: an essential attribute to spermatozoa. Journal of Andrology 33: 536-551.

Kar S, Divyashree BC, Roy SC (2015) Temporal leakage of $\mathrm{Cu}, \mathrm{Zn}$ superoxide dismutase and loss of two low-molecularweight forms of glutathione peroxidase-1 from buffalo (Bubalus bubalis) sperm after freezing and thawing. Theriogenology 83 : 512-519.

Kim SH, Yu DH, Kim YJ (2010) Effects of cryopreservation on phosphatidylserine translocation, intracellular hydrogen peroxide, and DNA integrity in canine sperm. Theriogenology 73: 282-292.

Leahy T, Rickard JP, Aitken RJ, de Graaf SP (2016) Dpenicillamine prevents ram sperm agglutination by reducing the disulphide bonds of a copper-binding sperm protein. Reproduction 151: 491-500.

Mortimer ST, Mortimer D (1990) Kinematics of Human Spermatozoa Incubated Under Capacitating Conditions. Journal of Andrology 11: 195-203. DOI: https://doi.org/10.1002/j.19394640.1990.tb03228.x.

Mostek A, Dietrich MA, Słowinska M, Ciereszko A (2017) Cryopreservation of bull semen is associated with carbonylation of sperm proteins. Theriogenology 92: 95-102.

Muino R, Pena AI, Rodriguez A, Tamargo C, Hidalgo CO (2009) Effects of cryopreservation on the motile sperm subpopulations in semen from Asturiana de los Valles bulls. Theriogenology 72: $860-8$.

Neild DM, Brouwers JFHM, Colenbrander B, Aguero A, Gadella BM (2005) Lipid peroxide formation in relation to membrane stability of fresh and frozen thawed stallion spermatozoa. Molecular Reproduction and Development 72: 230-238.

Partyka A, Nizanski W, Bratkowska M, Maslikowski P (2015) Effects of N-acetyl-L-cysteine and catalase on the viability and 
motility of chicken sperm during liquid storage. Reproductive Biology 15: 126-129.

Peris S, Bilodeau JF, Dufour M, Bailey JL (2007) Impact of cryopreservation and reactive oxygen species on DNA integrity, lipid peroxidation, and functional parameters in ram sperm. Molecular Reproduction and Development 74: 878-892.

Robert M, Gagnon C (1996) Purification and characterization of the active precursor of a human sperm motility inhibitor secreted by the seminal vesicles: identity with semenogelin. Biology of Reproduction 55: 813-821.
Thomson LK, Fleming SD, Aitken RJ, De Iuliis GN, Zieschang JA, Clark AM (2009) Cryopreservation-induced human sperm DNA damage is predominantly mediated by oxidative stress rather than apoptosis. Human Reproduction 24: 2061-2070.

Watson PF (2000) The causes of reduced fertility with cryopreserved semen. Animal Reproduction Science 60-61: 481-492.

Zhu Z, Fan X, Lv Y, Zhang N, Fan C, Zhang P, Zeng W (2015) Vitamin $\mathrm{E}$ analogue improves rabbit sperm quality during process of cryopreservation through its antioxidative action. PLOS One 10(12):e0145383. DOI:10.1371/journal.pone.0145383. 